\title{
SOBRE LA CONSIGNA "RACIONALIDAD"
}

Carlos Pereda

Universidad Autónoma Metropolttana Azcapotzalco

La palabra "consigna" suele formar parte del lenguaje político; se trata de una indicación - a menudo de un exhortación, de un appellansa fin de evitar, defender o atacar, favorecer o desaconsejar una regla o un propósito. No pocas veces vivimos la urgencia de que los otros atiendan reclamos nuestros, que reiteradamente desoyen $o$, al menos, de que sepan qué pensamos con respecto a un conflicto. Para esto nos manifestamos proponiendo consignas. Cuando estas manifestaciones las integra un grupo numeroso, se hacen en la plaza pública; también, sin embargo, las pueden hacer unos pocos o, incluso, una sola persona en la intimidad de una conversación consigo misma; mi conjetura es: muchos conceptos funcionan como consignas volviendo una manifestación el discurso donde intervienen; la racionalidad está entre estos conceptos. Quiero, por eso, explorar algunas propiedades que caracterizan el funcionamiento de una consigna y, específicamente, las del concepto "racionalidad". Me concentro en cuatro de estas propiedades.

1. En primer lugar, una consigna es la presentación de una opción enfáticamente normativa. No se levanta una consigna en el vacio o cuando "todo marcha", sino frente a dificultades que se busca resolver, respecto a conflictos donde se juzga apropiado intervenir. Una consigna es una toma de posición: llama directamente a un curso de acción. La palabra 'consigna' y palabras como 'dificultad' o 'conflicto' son, en cierto sentido, correlativas: no usamos consignas más que en relación a dificultades y conflictos y, cuando estamos en estas situaciones, casi siempre apelamos a consignas. Con la consigna 'racionalidad' ¿qué alternativa defendemos?

Recuérdese algún desasosiego, alguna molestia: se nos presentan de diversas maneras. Tenemos irritaciones más o menos simples, digamos, surge una dificultad en relación a lo que estamos haciendo; además, como se dice, las dificultades no vienen solas y no pocas veces lo que 
comenzó siendo una simple duda se expande hasta volverse un conflicto. Por otra parte, una dificultad, un conflicto, pueden tener lugar en una persona (desacuerdos internos) o constituirse de modo explícito como una dificultad o un conflicto con los otros, o sea, como desacuerdos externos. Esta distinción no es excluyente; señala más bien dos perspectivas opuestas para abordar una dificultad o un conflicto, que dos clases diferentes de dificultad o de conflicto: nuestras dificultades o conflictos son un ejemplo claro de la interdependencia interno-externo. Cualquiera que sea el caso, se pueden enfrentar dificultades o conflictos desestimándolos arbitrariamente, y si tratan de acosarnos, se los esconde y si todavía insisten, se los reprime. En relación a la tarea de eludir dificultades o conflictos son conocidas varias técnicas: las dificultades y los conflictos, con uno mismo o con los otros, pequeños o gravísimos, pueden silenciarse, declarándolos sin sentido antes de atenderlos, "descalificándolos a priori" (en desacuerdos externos, expresiones como "extranjero", "de ideas anormales", "de color negro", "sexualmente desviado", "loco"... son síntomas de que estamos frente a una alternativa de descalificación a priori); otra técnica es el ataque general, el "odio abstracto": una lucha en contra que empieza rehuyendo distinguir y muy pronto acaba no admitiendo ninguna clase de razones (el odio abstracto es, además, un odio contagioso: se parte de una objeción hacia la manera de actuar de un individuo $y$, rápidamente, se pasa a combatir el país a que pertenece ese individuo y hasta su lengua). La técnica límite en esta manera de tratar dificultades o conflictos consiste en eliminar a aquellos que acusamos de provocar la dificultad o el conflicto.

Estas violencias - desde la mera arbitrariedad a la agresión directa-, $u$ otras parecidas, tienen una alternativa radical: admitir la dificultad, reconocer el conflicto, y poner en marcha una producción de argumentos, estando a la vez dispuestos, a menudo teniendo que estar dolorosamente dispuestos, a hacer depender de los mejores argumentos propuestos nuestra actitud frente a un problema; racionalidad es el concepto tradicional para nombrar esta segunda manera de actuar. Tenemos, pues, que el appellans "racionalidad" tiene como appellandum "producir argumentos", o hablando más discretamente: una solución a un problema es racional si esa solución se apoya en los mejores argumentos disponibles a los involucrados en ese problema.

2. En segundo lugar, con respecto a una consigna, la relación entre su appellans y su appellandum es dual: relaciones fácticas y contrafácticas. Una consigna puede llamar a cumplir una regla o a buscar cierta meta y su valor radica en que motiva, impulsa conscientemente a seguir esa regla o a lograr esa meta. Por otro lado, independientemente de 
cualquier realización fáctica del appellandum, una consigna está presente ya contrafácticamente en tanto medida de lo que hacemos. Cuando ambas funciones se conjugan, buscamos seguir una regla o alcanzar una meta y, a la vez, tenemos la regla o meta como la medida crítica de nuestras acciones actuales. Otras veces, en cambio, esto no es posible, por lo menos no lo consideramos posible a corto plazo, y la presencia fáctica o contrafáctica de aquello a que apunta una consigna se vuelve excluyente.

La relación entre el appellans "racionalidad" y el appellandum "producir argumentos" es, en este sentido, característica. La consigna "racionalidad" nos invita a dirimir nuestros desacuerdos argumentando y de esta manera realizamos fácticamente el appellandum de racionalidad en tanto resolvemos una dificultad o un conflicto con argumentos. Pero la presencia del argumentar no constituye un "test" - no es condición necesaria y mucho menos suficiente - para juzgar la racionalidad de una manera de actuar. Hay situaciones donde argumentar efectivamente, o incluso intentarlo, lejos de constituir una acción racional es señal inequívoca de miopía o ingenuidad, de una radical incomprensión de la situación en que nos encontramos. Los casos más claros son aquéllos en que la violencia se ha apoderado abiertamente de la situación. Por ejemplo, frente a un tirano, a un torturador o a un asaltante sería una muestra de ceguera intentar argumentar: "antes de que cualquier discusión empiece hay que construir las condiciones donde la argumentación se va a llevar a cabo". En estas situaciones, la violencia o las simples decisiones sustituyen al ciclo argumentativo. Pero si esa violencia o esas decisiones pretenden legitimarse, si buscan conformar instancias diferentes a meras arbitrariedades del poder -si pretenden ser "violencia racional" o "decisiones racionales"-, entonces, no se tiene otra alternativa que actuar teniendo como medida el actuar razonado, la praxis apoyada en la argumentación. Este apoyo puede realizarse de dos maneras. En sentido débil, el apoyo contrafáctico de la argumentación significa: aunque se suspenda la argumentación, se trabaja para ella, nos esforzamos por levantar el marco que la hará posible. El sentido débil de "contrafáctico" es otra palabra para "indirecto": directamente no argumentamos, pero la argumentación permanece, indirectamente, como la meta a conseguir. Muchas veces el apoyo contrafáctico tiene también un sentido fuerte: no sólo buscamos argumentar, sino que en esta búsqueda hacemos como si tal argumentación fuese posible y guiamos nuestra acción con los resultados de esta argumentación. Un movimiento revolucionario no puede sentarse a la mesa de conversaciones con un tirano so pena de suicidarse; pero puede actuar $-\mathrm{y}$ yo agregaría: y debe actuar si no quiere perder su legitimidad- siguiendo las 
conclusiones alcanzadas en una argumentación contrafáctica entre los diferentes participantes del conflicto. El sentido fuerte de "contrafáctico" es, pues, otra palabra para expresar "actuar como si". Por eso, incluso en periodo históricos donde la lucha por el poder aplasta cualquier tentativa de razonamiento, el ciclo argumentativo continúa siendo la medida ya presente que, contrafácticamente, apoya cada paso de la acción legítima. Un razonamiento paralelo puede hacerse con respecto a los desacuerdos internos. Frente a un conflicto podemos vivirnos tan ofuscados que hasta sospechemos de nosotros mismos, llegando incluso a pensar que nuestros razonamientos son, en realidad, "racionalizaciones" del conflicto: tentativas de ocultar afectos o intereses que no se quiere o no se puede confesar. Como prevención para no responder apresurada e insensatamente a ese conflicto, una posibilidad es aferrarse a conductas conocidas y ya probadas, deteniendo la plática con nosotros mismos. Pero quien sigue la consigna "racionalidad" buscará que esta suspensión de la argumentación sea temporal, hasta recobrar, por así decirlo, su equilibrio perdido. La argumentación no desaparece entonces, en su suspensión, sigue contrafácticamente en el horizonte hasta que, ya devuelto a la persona el control sobre sí misma, ésta podrá retomar los argumentos en cuanto realidad fáctica.

Las situaciones donde la violencia anula cualquier posibilidad efectiva de argumentar no son, sin embargo, las únicas donde no es posible, o por lo menos no es oportuno, argumentar. A menudo los niños no entienden un argumento $y$, lo que es más relevante todavía, en muchos encuentros personales, argumentar o buscar argumentar puede estropear vínculos decisivos que se han instaurado a lo largo de los años en trabajos y experiencias en común. Pero el silencio se apoya en las palabras y es sólo en el trasfondo de ellas que razona, confiesa o canta. Podemos callar si nos hemos aventurado a argumentar, si la argumentación, de alguna manera, está presente; fuera de la conversación no hay silencio sino, simplemente, no hay nada.

3. En tercer lugar, el uso de una consigna es transformativo. Partamos de algunos conceptos no transformativos: los conceptos de número impar, país escandinavo o regla del foot-ball son conceptos estables; independientemente del discurso donde se encuentren, estos conceptos tienen un sentido claro y delimitado. En el caso del concepto de país escandinavo, una de sus características es conformar un conjunto cerrado de paises, y sería imposible que se pudiese conformar tal conjunto si la expresión "país escandinavo" no tuviese un sentido fijo.

Los conceptos que se comportan como consignas varían, en cambio, según la situación, en relación a otros conceptos. Lo que configura el 
actuar de manera racional se determina en cada situación. $\mathrm{Y}$ ello en dos sentidos. Por un lado - ya lo vimos - se necesita juzgar cuándo hay qué efectivamente argumentar y cuándo la argumentación constituye sólo una instancia contrafáctica. Por otro lado, en cada ocasión hay que atender qué argumentos necesitamos. Si bien cualquier argumentación probablementie tiene - eso, al menos, considero- ciertos rasgos formales característicos, cada argumentación es específica. Lo que entendemos como constituyendo una argumentación se modifica en relación a las circunstancias que nos rodean: la precisión que se demanda en una plática entre matemáticos no es la misma que la esperada en el diálogo de dos enamorados; los materiales que en algunas discusiones familiares valen como prueba, muchas comunidades científicas ni siquiera los considerarian una sugerencia; la importancia sobre lo que se argumenta, sobrentendida en el argüir de alumnos y maestros, puede fácilmente problematizarse en el razonar entre colegas. Forma parte de haber comprendido el appellans racionalidad saber descubrir qué argumentación efectiva es pertinente $-s i$ es que es pertinente alguna- dada cierta situación.

4. En cuarto lugar, y como consecuencia de las dos características anteriores - la tensión fáctico-contrafáctico en las relaciones entre el appellans y el appellandum y el uso transformativo tanto del appellans como del appellandum —, podemos decir que lo que la consigna "racionalidad" interpela es, en última instancia, nuestra capacidad de juzgar.

Examinemos la petición de contar los números impares a partir de cierto número. Cualquiera que sabe lo que es un número impar, puede, a partir de cualquier número impar, digamos el 7 , continuar la serie correspondiente:

$$
9,11,13,15,17 \ldots
$$

Lo que cuenta y lo que no cuenta como parte de la serie está claramente delimitado y si alguien aprendió el concepto productos de la serie -en este caso, el de número impar- puede mecánicamente producir la serie. El adverbio "mecánicamente" subraya que la actividad de producir una serie se opone a actividades donde es necesario tantear, explorar, inquirir, examinar, sondear, ensayar, esto es, ejercer nuestra capacidad de juicio.

Precisamente, aquello a que nos convoca la consigna "racionalidad" desborda cualquier actividad mecánica; por un lado, como consecuencia del uso dual de su appellandum, quien sigue la consigna "racionalidad" necesita tantear, inquirir, examinar si se encuentra frente a un caso 
donde la argumentación constituye una instancia fáctica o contrafáctica; por otro lado, el uso determinante del concepto de "racionalidad" y el uso modificador del concepto de "argumentación" exigen un parecido tantear, inquirir, examinar. Como el viajero a quien se le ha indicado un rumbo pero que en cada encrucijada tiene que descubrir cuál es el camino concreto a recorrer, así, quien busca actuar según la consigna "racionalidad", siguiendo una dirección frente a cada caso concreto, será llevado a ejercer su capacidad de juicio para ir descubriendo lo que efectivamente tiene que hacer.

Por eso, por excesivamente mecánica, es necesario evitar la manera tradicional de construir la oposición entre racionalidad y violencia, por ejemplo, la manera como los teóricos del contrato social creen despedirse de la violencia. Para, digamos, Hobbes, Locke, Rousseau o Kant —en esta ocasión, formando un consenso- la alternativa entre violencia y racionalidad constituye una "disyuntiva originaria". Una vez hecha la "elección inicial", una vez firmado el contrato social, comienza la serie de elecciones secundarias: si nuestra elección inicial fue por la violencia, nuestras elecciones secundarias se harán en relación a distintos actos de violencia. Si elegimos, en cambio, entrar en el contrato social, nuestras elecciones secundarias se llevarán a cabo con respecto a series de acciones racionales. Seguir actuando racionalmente o seguir haciendo actos de violencia se vuelve entonces un dispositivo similar al que se articula cuando se cuentan números pares o impares.

Me detendré un poco a examinar los conceptos de elección inicial y disyuntiva originaria. Estos dos conceptos no sólo están en la base de las teorias del contrato social sino que, constituyendo también los presupuestos de nuestras discusiones más informales, son, considero, el modo más frecuente de confundir, en el sentido de "mecanizar" -incluso a nivel de la vida cotidiana-, las relaciones entre la violencia, la racionalidad y la argumentación: ${ }^{1}$ el concepto de elección inicial simplifica indebidamente estas relaciones y el concepto de disyuntiva originaria, contradiciendo nuestras experiencias más claras y frecuentes, quiere hacer del pasaje de la racionalidad a la violencia, un pasaje irrevocable.

1 Para las teorías del contrato social el appellandum de racionalidad no es directamente la producción de argumentos sino la vida social ya establecida; por eso, la elección inicial para realizar un contrato social y la disyuntiva originaria a que responde, tienen como función respaldar la autoridad, entregan legitimidad a cierta manera de conformarse una sociedad. La manera racional de resolver conflictos públicos nos remite, en pensadores como Hobbes, Locke, Kant y también, en cierto sentido, Rousseau, a ciertos procedimientos institucionalizados, no a la argumentación en general. No obstante, en las diferentes teorías políticas de los tiempos modernos, tarde o temprano, se abre un lugar para juzgar el abuso de estos procedimientos e incluso para cambiarlos. De esta manera, indirectamente, el appellandum de racionalidad vuelve a ser la producción de argumentos. 
Por lo pronto, el concepto de elección inicial no tiene ningún sentido claro con respecto a situaciones que no están explícitamente regladas. Únicamente se puede distinguir con nitidez entre una elección inicial y un conjunto de elecciones secundarias en relación a actividades construidas por un reglamento, como los contratos comerciales, el matrimonio, las carreras profesionales o los juegos. En estos casos, la elección inicial constituye la puerta de entrada en la actividad correspondiente. Cuando introduje la racionalidad como la alternativa de la violencia, afirmé que un ciclo argumentativo se pone en marcha como respuesta a una dificultad o a un conflicto. Pero dificultades y conflictos no constituyen ninguna clase de elección. Además se observará: en sentido estricto, un ciclo argumentativo se pone en marcha sólo como respuesta a un problema. $Y$ sin embargo, por ejemplo, una dificultad o un conflicto indirectamente también lo hacen poner en marcha al provocar inquietudes y reacciones que, a su vez, conducen a problemas y argumentos. (No nos confundamos: al aludir a conceptos como dificultad e inquietud o conflicto y reacción estamos eligiendo dos entre los muchos pares de conceptos que pueden constituir la génesis de un problema y de su respuesta - un argumento-, pero se podrían elegir otros conceptos; no busco, acentuar conceptos como dificultad o conflicto, sino ilustrar algunas de las fases en el proceso que nos conduce a problemas y argumentos.) Atendamos.

Un enunciado como: "en este trabajo me inquieta la siguiente dificultad" a menudo alude a la respuesta a un obstáculo particularizado, limitado a sí mismo, sin desarrollo, sin despliegue, en medio de un trabajo que "marcha"; su respuesta, la inquietud, es claramente dependiente de la percepción del obstáculo. Pero el carácter puntual de la dificultad no conlleva precisión ni su directa dependencia implica un real "amarre" al asunto propuesto: la carencia de ramificaciones de una dificultad proviene del desconocimiento que nuestra inquietud tiene de ella: una dificultad aparece, por así decirlo, como un agujero cuyos vínculos se desconocen. En cambio, en un enunciado como: "el conflicto en el que estoy en mi trabajo me ha llevado a las siguientes reacciones" se suele dar a entender que la delimitación del obstáculo ha desaparecido, se tiene mayor conocimiento de él aunque este conocimiento sea vago, inexacto; lo que hace que su correspondiente respuesta, las reacciones, sean actitudes imprecisas, tan ambiguas como el conflicto que las provoca. En una reacción no se distingue, no se analiza; reaccionamos "en bloque".

En esta manera de hablar, palabras como "dificultad", "conflicto", "inquietud" y "reacción" tienen como rasgo común pertenecer al discurso de nuestra "historia vivida": las dificultades y los conflictos los 
"sufrimos"; una dificultad nos "hostiga", nos "persigue", en un conflicto somos "tironeados por distintas fuerzas"; por eso, sus respuestas, inquietudes y reacciones establecen un continuo con la dificultad o el conflicto a que responden; entre una dificultad y una inquietud o entre un conflicto y una reacción no hay distancia. A veces una dificultad o un conflicto, apenas se atienden, comienzan a borrarse. Pero a menudo las dificultades o los conflictos son resistentes: se repiten las mismas inquietudes y los mismos conflictos y estas repeticiones indican que nuestra inquietud no alcanza, no entiende la dificultad que la provoca, que nuestras reacciones al conflicto se han vuelto "ciegas", se han "estancado". Se necesita dar un rodeo, buscar el lugar que le corresponde a nuestra dificultad, desarmar el conflicto, distinguir: tenemos que producir argumentos para transformar la dificultad o el conflicto en problema. Disponiendo de un problema ya es posible proponer y argumentar posibles soluciones.

Sería, sin embargo, confuso afirmar: "la argumentación rompe con la inmediatez de lo vivido" y nada más; la argumentación no sólo rompe con, entre otras vivencias, la vivencia de dificultades y conflictos, sino que también, en muchos sentidos, las continúa, buscando darles solución desde una perspectiva más prometedora. Precisamente, esta historia de continuidades y rupturas anula un concepto como el de elección inicial.

La elección inicial de jugar esta tarde al football y no al basketball es previa, externa al juego y no tiene nada que ver con él; ya jugando, el resto de las elecciones serán secundarias con respecto a la elección inicial y se llevarán a cabo a partir de las reglas del juego. Cuando se expresa una elección inicial, diciendo: "acepto jugar con ustedes al football" (o algunas otras palabras similares), se promete: "acepto todas las reglas constitutivas del football a partir de las cuales haré mis elecciones secundarias, esto es, jugaré". Por el contrario, nadie elige de esa manera vivir en sociedad y resolver, argumentando, sus dificultades y conflictos, nadie está, ni nunca ha estado, más acá de dificultades y conflictos, fuera de la sociedad, en un "estado neutro" o en un "estado salvaje, de violencia" desde donde se elige hacer un contrato social. La relación entre violencia y racionalidad es mucho más gradual, más llena de interrelaciones de lo que supone la imagen de un contrato social. Motivamos la racionalidad en formas de violencia para proponerla como su alternativa general: es a partir de dificultades, inquietudes, obstrucciones, malestares, contrariedades, desasosiegos, tropiezos, impaciencias, conflictos, reacciones, que nuestra capacidad de juzgar nos dice que es necesario construir problemas y argumentos.

Por otra parte, la relación entre la violencia y la racionalidad no sólo es más compleja sino también menos irreversible de lo que sugiere la 
imagen de un contrato social. Conversar, producir argumentos puede ser, también, una forma de la violencia. Cuando nos disponemos a resolver dificultades y conflictos argumentando, rompemos con la violencia, pero no estamos volviendo definitivamente la espalda a la violencia. Si tiene poco sentido hablar de elección inicial con respecto a situaciones que no están previamente delimitadas y regladas, mucho menos sentido tiene hablar de una "disyuntiva originaria" en relación a procesos que tampoco están previamente delimitados y reglados.

Por más a favor de la argumentación que se esté, no se sigue argumentando en lugar de proseguir con actos de violencia, en el sentido en que se siguen contando números impares y no pares o enunciando países escandinavos y no países centroamericanos, jugando al football y no al basketball. Si se está jugando al football (y no se es portero) la acción de tomar la pelota con las manos, propia del basketball, queda claramente excluida. Si frente a un problema intento, siguiendo la consigna "racionalidad", poner en marcha un ciclo de argumentos, la violencia no queda excluida de mis acciones, la violencia también puede apoderarse de la argumentación. El contrato social no deja a un lado la violencia en el sentido en que jugar al football deja a un lado jugar al basketball. Pues, jugar al football no puede ser en ningún caso una manera de jugar al basketball y argumentar puede ser, en cambio, uno de los modos como se articula la violencia: se producen argumentos que ocultan razones y persuaden cuando no convencemos. Y no hay ninguna regla general que permita, en cualquier caso, distinguir con precisión persuasión de convencimiento: no pocas veces, frente a la sospecha de estar en presencia de pseudo-argumentos, no tenemos otra opción que realizar vastas encuestas y finos sondeos para sopesar luego la información recabada y juzgar si nos encontramos en una argumentación o en una pseudo-argumentación, esto es, tenemos que poner una vez más a prueba nuestra capacidad de juicio.

Las cuatro condiciones anotadas para que un concepto funcione como consigna constituyen un modelo de racionalidad que invita, frente a cualquier conflicto, a enfrentarlo produciendo argumentos. Esta caracterización se opone a la manera de comprender la racionalidad según el modelo de un algoritmo. Elaboremos un poco este contraste.

Quien entiende racionalidad como un algoritmo se compromete a dar criterios formales de racionalidad, esto es, criterios precisos, fijos y generales. Las listas que se ofrecen de estos criterios varían. Algunas de las clases de criterios que más se mencionan, con respecto a la racionalidad de las creencias, son: (a) mi creencia es un juicio analítico o mi creencia no está en contradicción con ninguna de nuestras otras creencias; (b) mi creencia ha sido comprobada directamente o disponemos de un tes- 
timonio altamente fiable para apoyarla o mi creencia forma parte del conjunto de creencias que acepta mayoritariamente la comunidad científica pertinente. En cuanto a las clases de criterios ofrecidos para medir la racionalidad de nuestras acciones, están entre las más citadas: está claro con respecto a las reglas que seguimos o a los fines que buscamos; en caso de un conflicto entre reglas o fines damos prioridad a las de mayor jerarquía; las reglas generales o los fines últimos son compatibles; utilizamos los medios adecuados para cumplir con esas reglas o alcanzar esos fines.

¿Qué decir de estos criterios? La primera clase concierne a los materiales lógicos de una argumentación. Incluso podría ser una manera de expresar los principios de identidad y no contradicción y, en este sentido débil de entender esta clase de criterios, quien busca no seguirlos ni es irracional ni se entrega a la violencia, simplemente no entiende lo que está creyendo o haciendo. Entre los "juicios analíticos", sin embargo, junto a las tautologías, suelen incluirse sinonimias y definiciones, pero no me imagino qué falta a la racionalidad constituye, en general, no aceptar una sinonimia o una definición (o incluso no aceptar el concepto de sinonimia, de definición y hasta de juicio analítico). Además, el principio de no contradicción usado para medir la irracionalidad no es excesivamente operante en la práctica. Podría tener, y seguramente tengo, muchas creencias inconsistentes que ignoro pero, una vez que las sé, intentaré evitarlas: yo no puedo creer que Guadalajara es la capital de Jalisco y al mismo tiempo creer que Guadalajara no es la capital de Jalisco. No se me puede pedir que no haga lo que de todas maneras no puedo hacer. A veces hay situaciones, sí, donde me encuentro en una encrucijada de creencias: recordemos a G. H. Moore enfrentado a la paradoja del análisis; de pronto se le mostraba que el método usado. durante toda su vida sólo podía obtener o trivialidades o falsedades. ${ }^{2}$ Un rigorista podría decretar: desde el momento en que Moore no podía eliminar la paradoja, no hubiera debido más echar mano a tal método so pena de pensar deshonestamente en la mayor de las inconsistencias; yo pienso, en cambio, que Moore actuó muy razonablemente al dejar la paradoja de lado y seguir trabajando. Podemos describir su situación

2 En The Philosophy of G. E. Moore, Nueva York, The Library of Living Philosophers, $2^{\mathrm{a}}$ ed. 1952, C. H. Langford, en su contribución "The Notion of Analysis in Moore's Philosophy", afirma: "El análisis establece una relación de equivalencia entre el analisandum y el analisans. Y la paradoja del análisis consiste en que, si la expresión que representa el analisandum tiene el mismo significado que la que representa el analisans, el análisis establece una simple identidad y es trivial; pero si las dos expresiones no tienen el mismo significado, entonces el análisis es incorrecto" (p. 323). En sus respuestas, G. E. Moore sin, al parecer, perturbarse demasiado confiesa: "Ignoro en absoluto cuál es la solución a esta paradoja" (p. 665). 
como una tensión entre las virtudes "consistencia" y "productividad": tal vez Moore pensó que no resolver la paradoja no le ocasionaba una inconsistencia demasiado grave y arrinconarla le permitía, en cambio, continuar con su programa de trabajo que él consideraba altamente prometedor.

Si atendemos a la segunda clase de criterios, que alude a la producción de nuestra información empírica, es fácil imaginar ejemplos donde estas instancias entran en contradicción. Pero incluso si las tres instancias se encuentran en perfecto acuerdo, ello no es necesariamente prueba inequívoca de nada. Cualquier hombre de principios del siglo xvI podría comprobar directamente que el sol se muere alrededor de la tierra - es lo que vemos cada día-; disponía de los testimonios más fiables para apoyar esa creencia - las mayores autoridades intelectuales del pasado y del presente, Aristóteles y la Iglesia, así lo afirmaban-; y era una creencia aceptada mayoritariamente por la comunidad astronómica del momento. $¿$ Tenemos que concluir, entonces, que el programa copernicano tenía que ser necesariamente juzgado como un claro ejemplo de creencias irracionales?

La tercera clase de criterios concierne a nuestras acciones y da una imagen bastante extraña de la vida humana: se piensa en algo así como una hermosa tarde de primavera; pero ¿cuándo? cada persona debe tomar un cuaderno y comenzar a anotar allí sus reglas más generales y sus fines últimos y dedicar luego un tiempo a precisarlos; pero de nuevo ¿cuándo? juzgar su compatibilidad, establecer jerarquías entre ellos, si fuera posible, incluso axiomatizarlos: por aquí la regla de la promesa, por allá la de mi amor a los padres, más abajo, tal vez, la de respetar a mis vecinos o solidarizarme con mis compañeros de trabajo. De nuevo nos encontramos con la ilusión de elecciones iniciales y disyuntivas originarias, con la pesadilla de que, una vez puesto en marcha un proceso, es necesario proseguirlo suceda lo que suceda - como si hechas ya ciertas elecciones, fuéramos por la vida con los ojos vendados, sin la posibilidad de nuevas experiencias, sin poder aprender. Las cosas, sin embargo, no suceden de este modo; sobre todo, este punto de vista estático de describir una vida la distorsiona básicamente. Consideraciones parecidas pueden llevarse a cabo en relación a la aplicación de reglas o fines, donde se olvida que los conflictos que nos presenta, por ejemplo, la aplicación de una regla que considerábamos no dudosa, tal vez nos haga revivir una actitud acerca de esa regla; y algo similar sucede también con las relaciones entre medios y fines.

Estas objeciones, sin embargo, no pretenden sugerir que las tres clases de criterios propuestos en ningún sentido son criterios de racionalidad, sólo que no lo son en tanto criterios formales. 
Un criterio formal da condiciones necesarias y suficientes. Podemos dar condiciones necesarias y suficientes para reconocer tíos o triángulos: un tío es una persona masculina que tiene sobrinos o sobrinas y un triángulo una figura geométrica de tres lados; en este sentido, recuérdense también nuestros ejemplos de número impar, regla del football o país escandinavo. Ninguno de los criterios anotados permite juzgar la racionalidad de esta manera.

Una persona puede en un momento actuar muy racionalmente no aceptando los juicios analíticos, la experiencia directa, las opiniones mayoritarias en una comunidad científica; lo hace cambiando de fines cuando está a punto de conseguirlos o negándose a poner en práctica ciertos medios, incluso aunque ellos constituyan la única posibilidad de alcanzar los fines queridos. Pero cuidado: fácilmente se desemboca en un modo de pensar subrayadamente arbitrario si no se siguen nunca estos criterios, más todavía, la arbitrariedad es inevitable si algunos de estos criterios no guían a menudo los pensamientos y las acciones. Por ejemplo, la segunda clase de criterios, la que concierne a la obtención de las informaciones empíricas - confrontación directa, testimonios fiables y creencias aceptadas por la comunidad científica-, sin duda no carece de dificultades, pero de un modo u otro tenemos que apoyarnos constantemente en ella. Quiero decir: por más veces que se tenga la experiencia de que un dato de los sentidos o un testimonio que se creía firme o una creencia cientifica engaña, no disponemos de otra alternativa que recurrir a esas instancias de información empírica; con los otros criterios pasa algo parecido.

Hay dos maneras, pues, de hacer uso de un criterio, o si se prefiere, hay dos clases de criterios. La primera radica en poder aplicarlo mecánicamente en cualquier situación, esto es, el criterio nos da condiciones necesarias y suficientes: hablo en estos casos de usos formales de un criterio, o más simplemente, de criterios formales; un criterio formal es una guía rígida, una regla infalible. La segunda manera de usar criterios o la segunda clase de criterios nos sigue ofreciendo una guía pero no elimina la incertidumbre de tener que pensar cada caso, en cierta medida, por sus propios méritos: hablo en estos casos de usos argumentales de un criterio o de criterios argumentales. En lugar de dar condiciones necesarias y suficientes para describir un estado de cosas, los criterios argumentales proporcionan materiales para considerar en un reconocimiento, pero sin poderlo determinar; hablando de otra manera: los criterios argumentales constituyen el marco para llevar a cabo una argumentación, son condiciones para tener necesariamente en cuenta en la argumentación.

El modelo de racionalidad como algoritmo piensa las creencias y ac- 
ciones racionales como la puesta en marcha de cierto mecanismo cuyo funcionamiento está asegurado por condiciones necesarias y suficientes; el modelo de racionalidad en tanto consigna se vincula, en cambio, a la idea de un hombre razonable que de argumentación en argumentación en alguna medida tiene que explorar lo que es necesario creer y hacer. Por eso, podemos también describir a los criterios de racionalidad, en tanto criterios a tener en cuenta, como las virtudes de un hombre razonable.

Se objetará: al pasar de un modelo de racionalidad como algoritmo a un modelo de racionalidad como consigna se escapa el suelo firme bajo nuestros pies, perdemos totalmente cualquier grado de precisión. Respuesta: si mis argumentos son correctos, y los criterios examinados no pueden comportarse como criterios formales, lo único que se escapa bajo nuestros pies es un suelo que nunca tuvimos. El modelo de racionalidad en tanto consigna no hace perder, pues, ninguna precisión, sólo la ilusión de tenerla.

De ahí que las condiciones anotadas para que un concepto funcione como consigna (su proponerse como una opción enfáticamente normativa, la tensión fáctico-contrafáctico en las relaciones entre el appelans y el appellandum, el uso transformativo tanto del appellans como del appellandum, la capacidad de juzgar como el interpelado en última instancia por la consigna) no son escollos que tendríamos que dejar atrás de alguna manera, por el contrario, son las propiedades de este uso de conceptos. El lenguaje no es un mar deshabitado y estéril donde en cualquier parte que se analice se encontrará $\mathrm{H}_{2} \mathrm{O}$. La pasión por la precisión, como cualquier pasión fundamental, merece no sólo nuestro apoyo sino también nuestra alerta para no convertirla en pasión ciega y, a la postre, en pasión vana. La búsqueda de precisión que no aclara nada y que incluso deforma el asunto que estamos tratando es una pasión vana. Un appellans tiene la función específica de exhibir y defender determinadas necesidades del hablante y esta función no podría cumplirse si intentáramos, por ejemplo, eliminarle su carácter transformativo y fijar estos conceptos en un algoritmo. No puede haber una sola clase legitima de conceptos desde el momento en que reconocemos varias clases legítimas de necesidades.

Importa, en cambio, cuidarse de los escollos reales que acosan a los conceptos consignas. Una confusión sería pensar que hay una clase de conceptos que, teniendo esas características anotadas, funcionan como consignas. Ello no es verdad en varios sentidos. Por un lado, muchos conceptos que a menudo se comportan como consignas pueden tener usos más inocentes: la palabra "libertad" o sus derivados "libre", "libremente" suelen usarse como consignas pero un taxi con el cartel "libre" 
no está habitualmente efectuando ninguna manifestación. Por otro lado, algunos conceptos que no se usan en tanto consignas, pueden, dada una situación, volverse consignas. La expresión " $30 \%$ de aumento" integra muchos discursos plácidos y sin sobresaltos. Pero es posible también que se vuelva parte de una consigna: en este caso, seguramente la cifra " $30 \%$ " no indica más la información exacta de lo que se pide, sino el anuncio de una posición desde donde empezar a argumentar -a negociar. También el concepto de casa cuando contribuye a conformar enunciados como "enviaremos a los niños una semana a la casa de su abuela" o "en la casa de enfrente vive un dentista", tiene un uso calmadamente informativo. Pero este concepto se puede usar también como consigna. Imaginemos la protesta de la familia Rodríguez ante un vendedor de inmuebles: "Pero esto no es una casa, es una cueva". En esta situación, el concepto de casa articula una opción enfáticamente normativa; hay un conflicto, y se levanta como consigna cierta manera de entender las cosas; una casa que no cumpla con esos requisitos no es una casa. El appellans "casa" comienza a tener como appellandum "casas que cumplan con ciertos requisitos". La familia Rodríguez seguramente es una familia que ya tiene una vivienda y quiere otra mejor, por eso rechaza la que le ofrecen a partir de un uso contrafáctico (en su sentido débil) de casa. Pero la medida que la familia Rodríguez tiene de los requisitos que mínimamente debe cumplir una casa puede seguirse modificando a partir de las experiencias que esa familia va haciendo: en cierto momento quizá basten dos habitaciones para distribuir padres e hijos en lugares diferentes; con el tiempo acaso se entienda que una casa no puede dejar de tener como condición mínima una habitación para cada hijo. Por otro lado, en condiciones habituales tenemos un uso con tendencia serial de casa: cuando decimos "en la casa de enfrente vive un dentista", no importan cuántas habitaciones tiene esa casa ni como se distribuyen en ella sus habitantes. De pronto, en cambio, la familia Rodríguez introduce razones para juzgar que no estamos frente a una casa; reconocer una casa deja de ser una actividad parecida a hallar el próximo número par después de 42 para exigir de nosotros argumentos, tanteos, exploraciones. En este sentido, una descripción más completa de la disputa entre la familia Rodríguez y el vendedor de inmuebles debería incluir un concepto crucial en relación a las consignas: diríamos que la familia Rodríguez protesta porque se encuentra ante la falsificación de una casa. Un concepto que forma parte de un algoritmo puede ser incorrectamente aplicado pero no tiene sentido decir que se lo falsifica. En cambio, en relación a los conceptos que funcionan como consignas, su escollo más peligroso es el acecho constante de la falsificación.

Es necesario distinguir este fenómeno de la inadecuación, incorrec- 
ción o mero error. Una cueva que se presenta como casa es un engaño pero una casa que es ofrece como casa del siglo xvin pero que fue construida hace apenas unas semanas, por bella y adecuada para vivir que sea, es también un engaño; un cuadro malo de de Picasso es un cuadro de Picasso pero los buenos falsos Picassos no constituyen ninguna clase de cuadiros de Picasso. Dada una situación podemos juzgar que es incorrecto levantar cierta consigna o tal vez que su defensa se apoya en enunciados falsos. Pero muy distinto es sospechar que se ha falsificado la consigna. Siguiendo la consigna 'racionalidad' argumentamos para resolver desacuerdos ofreciendo materiales que apoyan ciertos enunciados y convencen o nos convencen; paralelamente, en el pseudo-argumentar se entregan materiales que parecen apoyar ciertos enunciados y realmente no los apoyan pero persuaden o nos persuaden. Persuadir es "violentar" un convencimiento: es alentar, recomendar, incitar, o directamente inducir ciertas creencias o incluso, algún curso de acción, haciendo creer que se tienen bases para ello pero sin tenerlas. Por eso, el pseudoargumentar, la falsificación de la argumentación es un proceso que externamente se parece al argumentar —no se grita ni se amenaza sino que se razona- pero es un razonamiento con el cual, a veces sutil, a veces crudamente, se disfraza la violencia. Por ejemplo, persuadimos cuando usamos argumentos en cuyas premisas se mezclan deseos con enunciados confirmados o en donde la vaguedad de alguno de los términos sugiere inferencias, en realidad, inadmisibles; en muchas ocasiones, si bien cada argumento en particular es correcto, lo que confunde es la manera de articular los argumentos: si deseo que un amigo se decida por una acción y le presento sus consecuencias positivas, escondiéndole los éfectos poco satisfactorios, yo puedo no haber afirmado nada falso ni haber hecho ninguna inferencia incorrecta pero lo estoy engañando. Por eso, muchas veces, distinguir el argumentar del pseudoargumentar es una tarea difícil: lo que hace de una argumentación una pseudo-argumentación puede ser en el límite, simplemente, la situación en la que se lleva a cabo. En cualquier caso, el pseudo-argumentar frustra la invitación del appellans "racionalidad": la conversación ha dejado de ser la alternativa de la violencia para convertirse en una de sus formas. No obstante, la violencia discursiva, el pseudo-argumentar - desde las técnicas de los viejos sofistas a las de la propaganda modernano acompañan a la racionalidad, al argumentar meramente como su contra-ejemplo, tambiẻn como su homenaje: se falsifica la moneda que vale. 